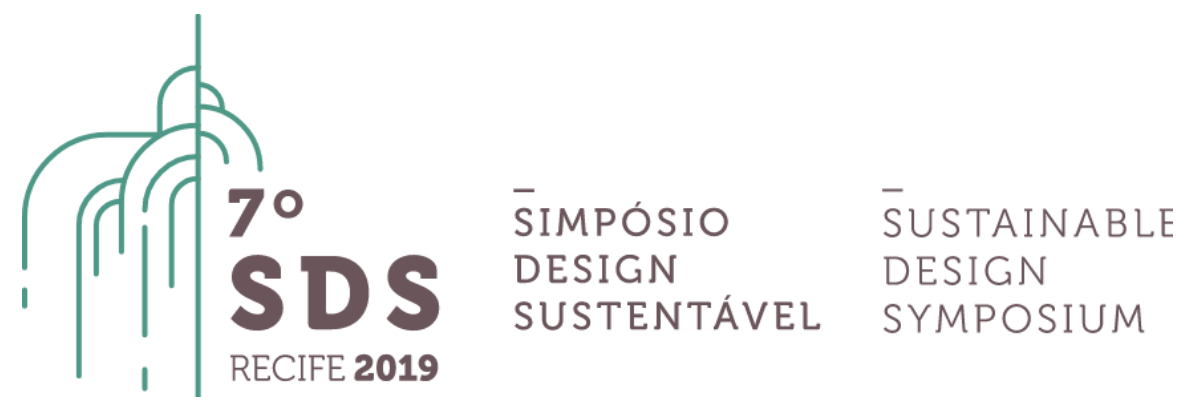

\title{
Codesign e Educação Patrimonial: Reflexões sobre futuros possíveis para o centro histórico de São Luís-MA
}

\author{
Nathalia Rodrigues Pinheiro ${ }^{1}$, Maria Luiza Lopes de Oliveira Santos ${ }^{2}$; Raquel Gomes Noronha ${ }^{3}$ \\ 'Universidade Federal do Maranhão - UFMA, DEDET, nathaliapinheiro01@gmail.com \\ 2 Universidade Federal do Maranhão-UFMA, DEDET, mllo.santos@ufma.br \\ ${ }^{3}$ Universidade Federal do Maranhão - UFMA, DEDET, raquelnoronha79@gmail.com
}

\begin{abstract}
Resumo. A humanização nos processos de Design e sua vertente colaborativa deram origem ao codesign, que será tratado no presente artigo como abordagem metodológica de campo. O objetivo desta pesquisa é propor reflexões sobre inciativas colaborativas de codesign implementadas em centros urbanos e sua possibilidade de adaptação à realidade social do centro histórico de São Luís-MA. Através de revisão bibliográfica foi traçado um panorama conceitual sobre o codesign e a educação patrimonial, o que fundamentou a análise de dois estudos de caso que apresentam alternativas colaborativas de intervenção urbana passíveis de adequação à perspectiva patrimonial, as iniciativas e métodos utilizados se apoiam em teorias de designers como Halse(2016), Ventura et. al(2016) , Manzini(2017) e Spinuzzi(2005). Os resultados encontrados mostram que qtravés da análise das iniciativas bem-sucedidas que foram apresentadas na Dinamarca, e no Rio de Janeiro no viés urbano e ambiental, é possível prever um itinerário educativo no que tange o patrimônio que possa ser adaptado também a sítios históricos e que seja efetivamente colaborativo.
\end{abstract}

Palavras-chave. Codesign. Educação Patrimonial. Metodologia. Preservação. Sustentabilidade.

\section{Introdução}

A cidade de São Luís - MA possui parte significativa de seu acervo arquitetônico histórico reconhecido nacionalmente como patrimônio material o que compreende um total de 5.600 tombamentos, dentre esses, 1.400 imóveis estão inscritos na lista do Patrimônio Mundial da UNESCO (FIGUEIREDO; VARUM; COSTA, 2011) por atenderem aos seguintes critérios de seleção:

(iii): ser um singular, único, ou pelo menos excepcional testemunho de uma tradição cultural ou de uma civilização viva ou desaparecida; (iv): ser um extraordinário exemplo de um tipo de construção, de um conjunto arquitetônico ou tecnológico ou de paisagem que ilustra um estágio significativo da história humana; (v): ser um extraordinário exemplo de um assentamento humano tradicional representativo da interação humana com o meioambiente (IPHAN, 2008, p. 14). 
Os critérios que definem a patrimonialização de um bem são os mesmos que justificam a necessidade e a importância de sua preservação, uma vez os bens patrimoniais incluem aspectos simbólicos, culturais, sociais e espirituais inerentes ao ambiente histórico. Diante disso, nos últimos anos a questão do patrimônio material e imaterial se fundiu com a preocupação com os problemas ambientais e de qualidade de vida. A sociedade reconhece cada vez mais que as gerações futuras se beneficiarão de proteção de ambientes e áreas, incluindo aquelas de herança patrimonial (PELEGRINI, 2006).

Diante de tal realidade a presente pesquisa busca integrar a questão da valorização do Patrimônio, por meio da Educação Colaborativa através de iniciativas sociais, que podem ser desenvolvidas através de métodos e ferramentas do Codesign. A partir de revisão bibliográfica de literatura percebe-se que para se fazer com que o campo da preservação patrimonial avance na construção de políticas públicas mais democráticas e sustentáveis seria preciso envolver as esferas da conservação em seus contextos específicos e a comunidade na proposição de estratégias educativas para solucionar carências.

Para conceituar e compreender a metodologia proposta e seus desafios, os principais autores utilizados foram Spinuzzi (2005) que conceitua o Codesign e apresenta seus desafios modernos, Papanek (1975), que defende que os designers são capazes de provocar mudanças reais no mundo, atuando como intermediadores da comunicação e inovação na sociedade, Mazini (2017) que pondera sobre o design e sustentabilidade social e a importância da valorização do agente comunitário no processo de Design uma vez que "todos são dotados de uma capacidade de fazer design, mas nem todos são designers competentes, e poucos se tornam designers profissionais" Mazini (2017, p. 51), além dos conceitos propostos por Ehn (2017) que trata o design participatório como um curso entre tradição e transcendência, de forma que a valorização de saberes tácitos promova a preservação das culturas.

As conceituações que tangem a educação patrimonial foram norteadas pelas definições que o IPHAN (Instituto do Patrimônio Histórico e Artístico Nacional) apresenta sobre o valor do patrimônio e seus meios para preservação, além de trabalhos acadêmicos já desenvolvidos que reúnem valiosas contribuições históricas como Costa (2016), que permitiu uma percepção crítica sobre as iniciativas educativas que já foram implementadas em São Luís-MA desde 1995.

Através do estudo de caso de iniciativas de práticas de atividades colaborativas que aconteceram como produtos de Codesign em uma pesquisa realizada na Dinamarca, financiada por uma instituição privada e outra no Rio de Janeiro, promovida pela Universidade Estadual - (EsdiUERJ) este trabalho propõe reflexões sobre adequações à realidade urbana ludovicense. O objetivo geral da pesquisa é, portanto, levar-nos a compreensão de que a apropriação do espaço urbano através de Eventos de Design como sugere Halse (2013) ou de Cenários Orientadores de Design como proposto por Manzini (2017) estimula o cidadão a se envolver e participar de forma espontânea dos debates sociais, refletir sobre suas principais necessidades e carências, e assim propor espontaneamente soluções que possibilitem a preservação e manutenção de sua região de moradia, fator este que possibilita a adequação da metodologia para aplicação no viés educacional patrimonial, promovendo principalmente o engajamento social nesse processo.

Diante do exposto, o presente trabalho pretende contribuir para a área de Design através da elaboração de uma proposta de pesquisa que utiliza o Codesign como abordagem metodológica, a fim de promover a comunicação e aproximação de grupos sociais de diversos níveis de escolaridade com o ambiente científico para incentivo ao desenvolvimento urbano associado à preservação cultural. 


\section{Design Participativo/Codesign: conceitos e desafios para inovação social}

Embora o design participativo seja muitas vezes tratado como uma orientação de pesquisa ou um campo entendê-lo como uma metodologia nos leva a compreender melhor suas promessas e restrições, suas limitações e seus critérios (SPINUZZI, 2005). O termo Design Participativo é uma das primeiras expressões utilizadas para o que se entende hoje sobre as atividades colaborativas implementadas nos processos de Design, que evoluiu para o termo Codesign, uma vez que a expressão Design Participativo tem sua origem nas lutas sindicais contra processos de implementação de sistemas de automação na indústria na Escandinávia dos anos 70 e a centralidade deixou de ser o ambiente de trabalho e o trabalhador, para alcançar o espaço público e o cidadão (VENTURA; SZANIECKI; TIBOLA, 2017), buscando dessa maneira promover a difusão de saberes por meio da construção de processos autônomos e colaborativos em um ambiente e/ou território específico, como defende Manzini (2017) a seguir

\footnotetext{
Nesse processo de reavaliação ou redefinição da noção de trabalho, o valor e a força da colaboração reaparecem. Trata-se da precondição necessária para fazer algo acontecer e parar permitir às pessoas desempenharem um papel ativo na construção do futuro que escolheram. A maioria das soluções que essas pessoas inovadoras produz é baseada em colaboração (Manzini, 2017, p.38).
}

O Codesign passou por muitas mudanças ainda, variações posteriores afastaram-no dos fundamentos marxistas, mas seu núcleo e objetivo permaneceram. O objetivo de sua abordagem é examinar os aspectos tácitos e invisíveis da atividade humana, supondo que esses aspectos podem ser examinados de forma produtiva e ética por meio de parcerias com os participantes. Parcerias nas quais os designers e os participantes projetam, de forma cooperativa, artefatos, fluxos de trabalho (processos) e podem juntos propor novos produtos e ideias, essa parceria deve ser conduzida de forma seletiva para que os pesquisadores possam desenvolver e refinar sua compreensão da atividade (SPINUZZI, 2005). Diante disso, percebe-se que se torna invisível a hierarquia no ambiente de pesquisa e trabalho colaborativo, o que proporciona uma troca conhecimentos bilateral e espontânea por todos os envolvidos, orientando desta maneira, um curso "entre tradição e transcendência" (EHN, 1989, p. 28) conduzindo através de um viés ético e humano o processo de pesquisa para uma proposta educativa de intervenção social mais efetiva.

Dessa forma, o Codesign se desenvolveu como prática onde são reunidas as habilidades do designer e o conhecimento tácito dos co-pesquisadores que participam ativa e diretamente nos processos de transformação da realidade, de modo que o projeto construído encontra-se alicerçado na experiência dos participantes e, ao mesmo tempo, fornece recursos que os capacitam a agir autonomamente sobre seus problemas.

A metodologia do Codesign é, portanto, derivada da pesquisa-ação participativa, pois pode ser também conceituada como "Investigações intervencionistas práticas" (EHN, 1989, p. 13), em oposição à coleta de dados e reflexão teórica tradicional, pois neste tipo de abordagem os designers são vistos como facilitadores que tentam motivar os participantes a tomar suas próprias decisões. Para Papanek (1971), designers têm a responsabilidade de provocar mudanças reais no mundo. Dessa forma, o Codesign envolve redesenhar não apenas novos locais de trabalho, mas reconstruir em conjunto toda a experiência de criação e organização de produtos e processos, de forma interativa, pois permite que trabalhadores, agentes comunitários e pesquisadores examinem criticamente os impactos dessas reformulações em andamento (SPINUZZI, 2005).

Essa abordagem metodológica do Design apresenta pontos fortes no que diz respeito ao resultado da pesquisa, pois envolve confiança e alteridade dos envolvidos no processo, o que já é um resultado de pesquisa relevante, pois compreende a apreensão das perspectivas sócio-culturais 
de um grupo social. No entanto, existem compensações e desafios significativos que precisam também ser levados em consideração neste processo de abordagem,

\begin{abstract}
Por exemplo, os pesquisadores precisam recorrer frequentemente a métodos etnográficos para adquirir conhecimentos sobre o campo de trabalho, às ferramentas e as tradições artesanais dos participantes. No entanto, estes pesquisadores que muitas vezes vêm de contextos de projeto de sistemas, interação humano-computador ou comunicação técnica e tecnologia tendem a aplicar esses métodos de forma bastante imprecisa aos olhos de etnógrafos treinados (Tradução nossa, Spinuzzi, 2005, p. 165).
\end{abstract}

Dessa forma, os principais desafios estão relacionados principalmente a alteridade e confiança estabelecidas entre os envolvidos nesse processo de criação e pesquisa, uma vez que a participação dos agentes comunitários ou quaisquer outros envolvidos depende primariamente da relação de confiança a ser estabelecida, pois a abordagem tem um caráter de pesquisa ação e, no entanto, se utiliza de métodos da pesquisa etnográfica, o que exige dessa abordagem um espaço de tempo e cronograma que sejam flexíveis e uma resoluta atenção, compromisso e dedicação com o campo de pesquisa por parte do pesquisador.

A esse processo de Design colaborativo com práticas coletivas, cujo objetivo é estimular os usuários, habitantes e demais envolvidos no processo a refletirem sobre questões sociais, ambientais, preservacionistas e sobre problemáticas usuais do seu entorno e cotidiano, para proposição coletiva e experimentação de soluções "para um futuro possível" (HALSE, 2011, p. 310), Halse (2011) contribui denominando esse de processo de "Etnografias do Possível", em que o pesquisador se apropria da sensibilidade descritiva da pesquisa antropológica e junto a um grupo ou comunidade propõe intervenções criativas, próprias do Design e que sejam culturalmente aceitáveis.

O desenvolvimento das atividades deve acontecer em pequenos grupos reunidos em ambientes criativos, que facilitem a comunicação e o engajamento, esses ambientes serão ferramenta principal de trabalho e os trataremos como "Eventos de Design ou Eventos de Transformação" (HALSE, 2011, p. 21) que funcionam da mesma forma que os "cenários orientadores de Design" Manzini (2017, p. 146). É neste ambiente colaborativo, que proporciona um engajamento sócio-cultural que Manzini (2017) pondera sobre a valorização do agente comunitário no processo de Design uma vez que "todos são dotados de uma capacidade de fazer Design, mas nem todos são Designers competentes, e poucos se tornam designers profissionais" (MANZINI, 2017, p. 51) tornando o produto desse processo uma efetiva construção coletiva, um produto de Codesign com resultados práticos para a sociedade.

\title{
3 Educação Patrimonial: conceitos e aplicações
}

Diante do atual contexto de reorientação para valorização da expressividade cultural e artística das minorias sociais para o reconhecimento do que se compreendem como Patrimônio Imaterial e Artístico Nacional as pesquisas nas universidades e institutos passaram a se envolver com as questões patrimoniais e a propor intervenções educativas para a população, a esse conjunto de pesquisas e processos formativos associamos à Expressão também adotada pelo IPHAN de Educação Patrimonial IPHAN (2008).

Segundo o guia de Educação Patrimonial preparado pelo IPHAN em 2008, o conceito tratase de um processo permanente e sistemático de trabalho educacional centrado no Patrimônio Cultural como fonte primária de conhecimento e enriquecimento individual e coletivo. A partir da experiência e do contato direto com as evidências e manifestações da cultura, em todos os seus múltiplos aspectos, sentidos e significados, o trabalho da Educação Patrimonial visa levar as crianças e adultos a um processo ativo de conhecimento, apropriação e valorização de sua herança cultural, 
capacitando-os para um melhor usufruto destes bens, e propiciando a geração e a produção de novos conhecimentos, num processo contínuo de criação cultural, como conceituado a seguir

A Educação Patrimonial é um instrumento de "alfabetização cultural" que possibilita ao indivíduo fazer a leitura do mundo que o rodeia, levando-o à compreensão do universo sociocultural e da trajetória histórico-temporal em que está inserido. Este processo leva ao reforço da auto-estima dos indivíduos e comunidades e à valorização da cultura brasileira, compreendida como múltipla e plural (IPHAN,2008, p. 19).

O conhecimento crítico e a apropriação consciente pelas comunidades do seu Patrimônio são fatores indispensáveis no processo de preservação sustentável desses bens, assim como no fortalecimento dos sentimentos de identidade e cidadania. A partir da compreensão das definições e expectativas sobre o que se quer alcançar ao se tratar a Educação Patrimonial e seus benefícios para a preservação urbana e ambiental, percebe-se que é imprescindível que toda ação educativa assegure a participação da comunidade na criação, aplicação e implementação, além da execução das atividades propostas. Expectativas, estas, que vão ao encontro dos objetivos da abordagem metodológica proposta nesta pesquisa.

O que se almeja, portanto, é uma "construção coletiva do conhecimento, identificando a comunidade como produtora de saberes que reconhece suas referências culturais inseridas em contextos de significados associados à memória social do local" (IPHAN, 2008, p. 69).

Nos últimos anos, multiplicaram-se iniciativas educacionais voltadas à preservação patrimonial. Nesse processo, as iniciativas educativas devem ser encaradas como um recurso fundamental para a valorização da diversidade cultural e para o fortalecimento da identidade local, fazendo uso de múltiplas estratégias e situações de aprendizagem construídas coletivamente. E ao se adotar a expressão Educação Patrimonial, uma grande variedade de ações e projetos com concepções, métodos, práticas e objetivos pedagógicos distintos foi realizada por todo o país.

No entanto, a cidade de São Luís-MA, ao longo dos últimos 10 anos tem apresentado resultados poucos eficazes no que diz respeito à aplicação de suas ações educativas no âmbito patrimonial, a aceitação por parte das comunidades é um aspecto questionável e posteriormente a isso, a manutenção de tais inciativas deixa a desejar, segundo Costa (2016)

\footnotetext{
As ações educativas são utilizadas com maior frequência por órgãos de preservação, ao longo do tempo. Estas vêm sofrendo modificações: no princípio, eram facilmente traduzidas e aceitas por intermédio da divulgação e informação realizadas por diversos meios; hoje, entretanto, se resumem apenas em divulgação e informação, sem sequer provocar reflexão e suscitar diálogo; são entendidas como ações de pouca ou nenhuma eficácia, muitas vezes traduzidas como orientação (COSTA, 2016, p. 47).
}

Partindo dessa realidade social, através desta pesquisa busca-se associar as metodologias do Design colaborativo de forma que se incentive a participação social para que as iniciativas educacionais não sejam restritas a órgãos institucionais ou centros de pesquisa, mas para que os próprios cidadãos ao se defrontarem com suas capacidades, potencialidades e direitos, eles também são responsáveis e capazes de zelar pelo patrimônio. O Codesign propõe uma diferente abordagem de construção de conhecimento, de forma que o processo de Design e o Processo Educativo se entrelaçam em uma mesma rede de pesquisa e o personagem educador/pesquisador/designer torna-se aprendiz das realidades e necessidades para que seja capaz de desenvolver junto a uma comunidade ou grupo específico, soluções criativas e inovadoras de intervenção. Pesquisando, testando e aprendendo continuamente.

A seguir serão apresentados estudos de caso de Codesign Urbano e por meio dos resultados positivos obtidos na implementação dessas atividades foi possível refletir sobre a aplicabilidade do método à Educação Patrimonial. 


\section{Espaços para o diálogo social}

Neste tópico foi possível fazer uma análise de algumas ferramentas de cocriação implementadas no Design urbano que apresentaram resultados satisfatórios, para que dessa forma seja possível prever adequações a serem reproduzidas no campo da Educação Patrimonial. Dentre as ferramentas a serem analisadas o objetivo de sua aplicação converge para o mesmo objetivo - aproximar e facilitar o diálogo entre os participantes da pesquisa, Mazini (2015) é um dos autores que incentiva a aplicação e reprodução de tais ferramentas, visto que:

Todo processo de Codesign inclui a cocriação de ideias comuns sobre o que fazer e como fazer. As ideias comuns surgem a partir de um diálogo entre os atores sociais interessados. Para iniciar e alimentar esse diálogo, diferentes ferramentas podem ser usadas para mostrar como o mundo poderia ser [...] Consequentemente, chamadas de temas de diálogo por serem concebidas para estimular reações e interações entre diferentes atores potencialmente interessados (MANZINI, 2015, p. 151).

Halse (2016), que defende que o processo da pesquisa é o próprio Design, justifica assim que o objeto da pesquisa está em constante construção, principalmente na pesquisa de caráter exploratório, uma vez que as ferramentas, técnicas, colaboradores e os resultados são expectativas do imaginário, e é necessário estabelecer uma relação de confiança e reciprocidade no ambiente de pesquisa, o mesmo autor apoia também o uso de experimentos lúdicos visto que eles favorecem uma abordagem confiável e prática em torno de uma questão social a ser problematizada:

Porque o objeto do design exploratório pertence em parte ao reino da imaginação e está além do ponto em que pode ser totalmente articulado, é bastante comum fazer experimentos com protótipos em situações da vida cotidiana realizadas sob o nome de laboratórios vivos, intervenções de projeto e ensaios de campo. O objetivo imediato destes experimentos é estabelecer e explorar uma abordagem confiável e significativamente prática em torno de uma questão particular e uma ideia para a sua resolução no ambiente de e pelas pessoas que aborda, antes que a ideia seja totalmente desenvolvida (Tradução nossa HALSE, 2016, p. 314).

Diante do exposto é possível notar a relevância e o aporte teórico que defende a essa forma de abordagem mais lúdica e espontânea, cujo objetivo é estabelecer relações bilaterais de confiança para que então seja possível a proposição colaborativa de dispositivos de inovação social que também sirvam de apoio à educação.

A seguir consta uma análise das implementações que aconteceram à nível nacional na ESDI/RJ e em nível internacional em uma pesquisa promovida por instituição privada, em que houve participação popular e municipal, na Dinamarca em 2008.

\subsection{Dispositivo de Conversação (Esdi-UERJ) - Caixa para troca de ideias}

Desde 2012 a Escola Superior de Desenho Industrial do Rio de Janeiro (Esdi-UERJ) tem implementado ações que procuram conectar design e cidade pelo viés da cidadania. A partir de iniciativas, em localidades do centro da cidade - próximo a localização da universidade - que os levaram a desenvolver ferramentas que estimulam a comunicação entre os habitantes dos bairros para promover o desenvolvimento colaborativo das pesquisas, tais ferramentas foram denominas pelos pesquisadores como Dispositivos de Conversação (VENTURA; SZANIECKI; TIBOLA, 2016).

Esses dispositivos são protótipos lúdicos, com ilustrações e perguntas sobre as circunstâncias da cidade e sugerem um ambiente de conversa sobre situações cotidianas, suas necessidades e expectativas, funcionam como canalizadores da criatividade viva da cidade e como recorte focal de memória do tempo, criando uma atenção provisória diferenciada para determinado espaço e estimulando o cidadão a refletir sobre a circunstancias sociais. 
As figuras $1 a$ e $1 b$ a seguir são fotografias de trabalhos realizados pela ESDI que proporcionam diálogos sociais de forma lúdica, tendo a caixa de isopor sido adaptada como ferramental ilustrado e lúdico, servindo como elemento físico para representar um Cenário de Design (MANZINI, 2017) e ponto para troca de ideias cujas anotações seriam transcritas em post-its e se tornam traduções da leitura do habitante pelo lugar. O que se percebeu através dessa iniciativa é que os próprios habitantes começaram a se questionar sobre o que poderia tornar o local mais atrativo e eles mesmos passaram a oferecer alternativas práticas sobre os elementos culturais, funções urbanas ausentes e fatores relacionados à educação ambiental.

Figura 1a e 1b - Dispositivo de Conversação
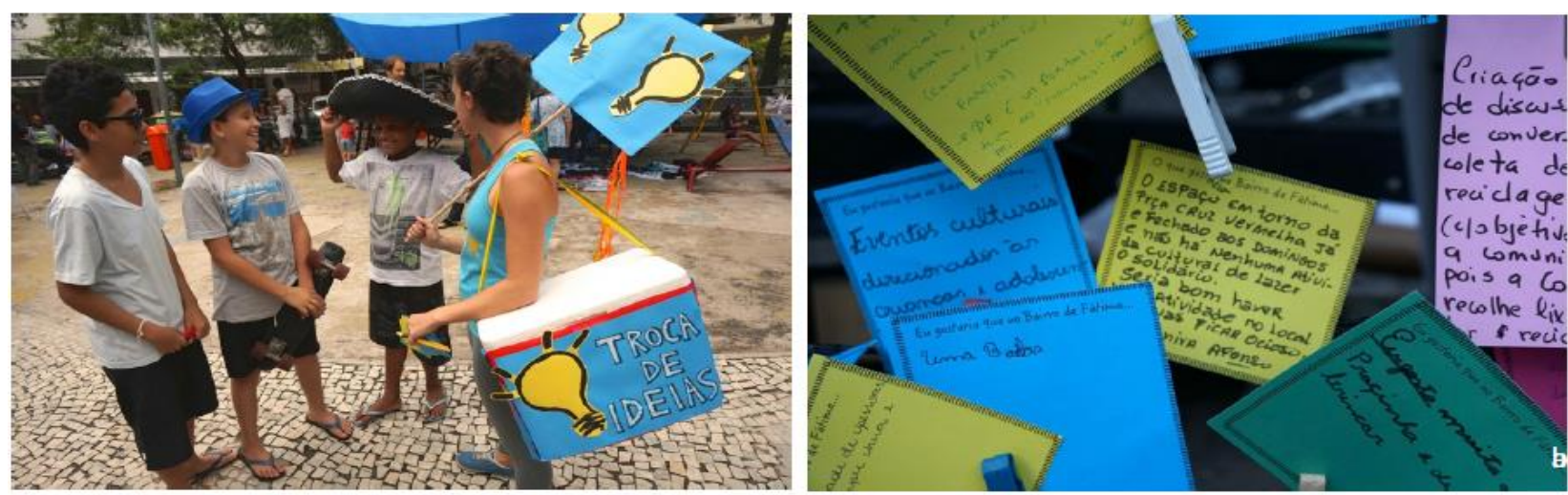

Caixa para troca de ideias - Feira de Doação, Bairro de Fátima,RJ

Fonte: Ventura; Szaniecki; Tibola (2016, p. 10)

Percebe-se que a simplicidade de execução, implementação e teste da ferramenta proposta acima favorece sua adaptação à outras iniciativas que precisam gerar engajamento e curiosidade por parte de uma comunidade específica, seja qual for o grau de escolaridade dos habitantes. Uma vez que tal ferramenta de comunicação aproxima de forma lúdica os envolvidos das questões sociais urbanas, sem interferir em seu cotidiano, tornando o diálogo espontâneo e convidativo, livre de hierarquias e rico na troca de alteridades. Atendendo dessa forma, às expectativas que os ambientes criativos de Design visam proporcionar. Diante das perspectivas promissoras de participação da comunidade através deste mecanismo de diálogo este poderia ser adequado para que os questionamentos tenham cunho educacional e de preservação e manutenção patrimonial, se adaptado a áreas centrais históricas das cidades, promovendo assim uma reflexão crítica sobre o papel do cidadão em sua localidade.

Como já comentado, parte significativa dos trabalhos e projetos já desenvolvidos na área da Educação Patrimonial, foram criados atendendo muitas vezes a interesses políticos ou governamentais, não levando em consideração a relação do habitante da comunidade com a proposta, dessa forma, o processo de manutenção da maior parte das iniciativas educativas foi ineficaz. O método acima referenciado aproxima agentes comunitários de todos os níveis de escolaridade, e torna horizontal o processo de aprendizado e troca de conhecimentos, fator que favorece a replicação do método em outros centros urbanos de variadas culturas.

\subsection{Oficina de Design Comunitária}

Em uma pesquisa realizada na Dinamarca em 2008, Halse (2013) relata que a Vestforbranding - indústria de incineração convidou uma equipe de pesquisadores de Design das Universidades e Empresas de Consultoria Profissional em Design, para explorar as práticas existentes e novas formas de manipulação de resíduos. $O$ projeto foi financiado em parte pelo 
programa do governo dinamarquês e por patrocinadores interessados.

O objetivo declarado do projeto foi envolver os cidadãos e demais interessados no projeto em diálogos orientados ao design para explorar e desdobrar potenciais melhorias nas práticas de manuseio de resíduos. O ambiente de reuniões e diálogo escolhido foi o Bangs Torv, um centro comercial de tamanho médio combinado com casas residenciais.

Foram utilizadas técnicas etnográficas como entrevistas semiestruturadas, acompanhamento da rotina de limpeza do zelador e transcrição do seu cotidiano. Além da criação de jogos de tabuleiro para criação de diálogo com os clientes no shopping e cenários com bonecas com proporções humanas para encenação de possibilidades e diálogos locais, mantiveram também um tipo de site para permitir e incentivar participantes a verem o que foi feito das histórias geradas pelo uso destes métodos mistos de pesquisa.

Paralelamente, criaram oficinas para incentivar a participação de membros do setor de resíduos profissional, eles deveriam formular suas versões de projetos e potencialidades para o futuro, para que fosse possível fazer um comparativo de perspectivas sobre o que era seria tecnologicamente possível e desejável a se fazer com os resíduos na perspectiva dos especialistas.

Após a coleta de todos os dados foi criado um ambiente para os envolvidos participarem, analisando colaborativamente os resultados dos dados e percepções na forma de uma oficina (figura 2).

Figura 2 - Oficina Colaborativa

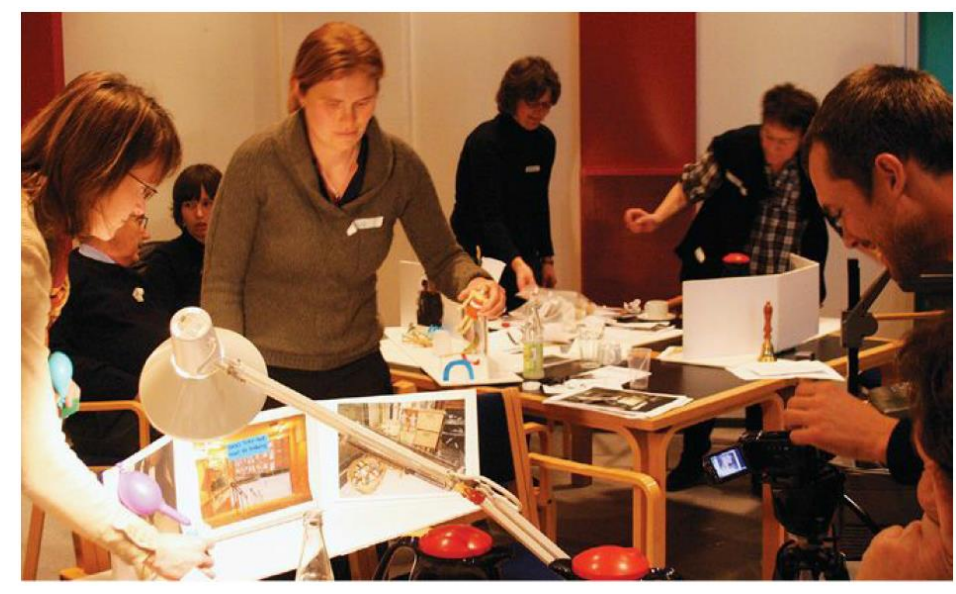

Ambiente de diálogo de Design, Dinamarca 2008

Fonte: Halse (2016, p. 524)

Em síntese, o processo teve dois ideais: primeiro conduzir os participantes a um reconhecimento do cotidiano e dos acontecimentos do shopping e segundo, tentar fazer conexões parciais entre as perspectivas futuras e sonhos de todos os participantes, a fim de compreenderem e refletirem sobre o que poderia ser melhorado, ou feito de forma diferente por eles mesmos para facilitar o manejo dos resíduos.

A oficina colaborativa foi um cenário de Design criado para promover a comunicação e participação de todos, dessa forma, não havia demonstrações de novas tecnologias, ou declarações autoritárias de quais os objetivos alcançar. $O$ ambiente de conversa, ou oficina de cocriação era uma sala em que havia uma grande quantidade de fotografias locais, ilustrações, croquis, esboços de ideias de Design e materiais espalhados para que todos os colaboradores pudessem manuseá-los sobre as mesas, junto com utensílios para transformá-los. As mesas eram dispostas em pequenas 
ilhas, o que sinalizava um grau de autonomia e independência de grupo.

As ferramentas utilizadas nesta modalidade de abordagem metodológica para comunicação em Design aplicada na oficina foram materiais simples como fotos de campo, esboços e papéis em branco para rabiscar, tudo para que os participantes fossem estimulados a criar histórias de possíveis futuros e os encenaram através de cenários curtos de boneca, que foram gravados em vídeo.

Esta proposta lúdica de Codesign permitiu que os envolvidos refletissem sobre a disposição dos equipamentos urbanos, sobre o local e disposição das lixeiras, sobre a forma como esse resíduo era coletado, e os cenários com as bonecas serviram como modelos de teste e protótipos para tornar ainda mais lúdicos e espontâneos os diálogos e preparar para a experiência pessoal de transformação urbana efêmera que eles mesmos realizaram, como ilustrado na figura 3, em que os colaboradores da pesquisa criaram um totem para teste de coleta seletiva utilizando cestos de supermercado, compondo uma estrutura flexível e leve, facilitando o transporte para outros pontos, pois identificaram que uma de suas maiores dificuldades em relação à coleta de lixo era o deslocamento para o ponto de coleta ou a pouca visibilidade que este tinha.

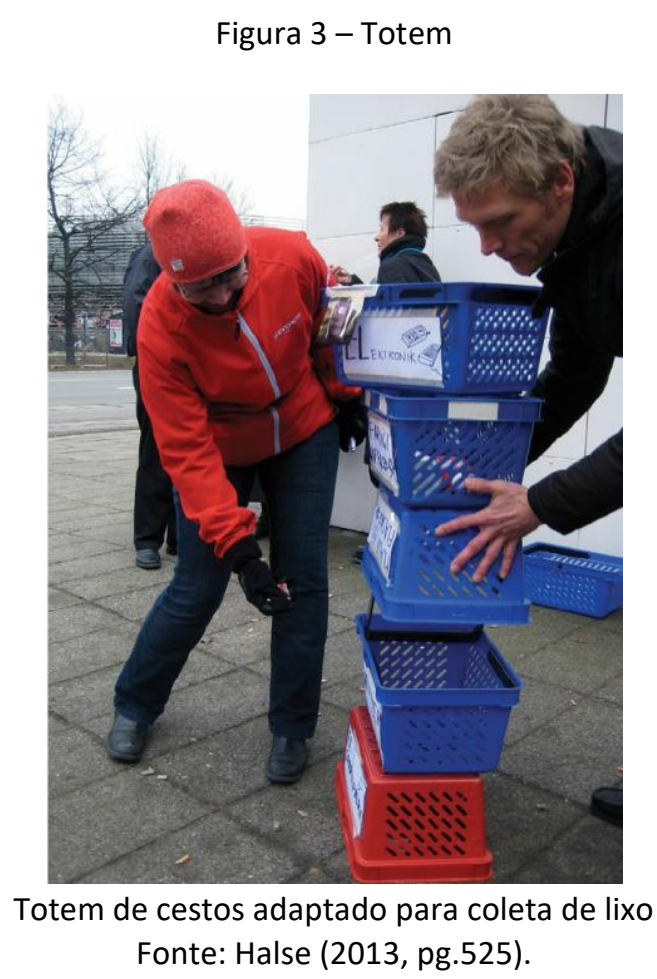

A iniciativa de pesquisa colaborativa relatada pelo autor recebeu a expressão de "Etnografias do Possível" (HALSE, 2013, p. 310), uma vez que se utilizou de uma abordagem antropológica, métodos de transcrição e entrevistas semi estruturadas, mas, no entanto, era um projeto que objetivada encontrar mecanismos para inovação social, preservação ambiental e gestão urbana por meio dos processos de Design colaborativo. Oportunamente, foi observada a eficácia da aplicação do método através do retorno e constante participação dos colaboradores na pesquisa, que envolveu agentes municipais, comunitários, designers especialistas ou não especialistas, todos engajados na causa de criar uma nova realidade para situação da coleta de lixo, que fosse mais econômica para a indústria e, no entanto, mais interessante e funcional para a comunidade.

Diante dos resultados promissores verificados ao longo da pesquisa em Bangs Torv, mesmo 
sendo estratégias que envolveram uma série de colaboradores interessados, de diversos níveis de escolaridade em um país desenvolvido, pode-se considerar sua replicação e adaptação em outros cenários de Design e realidades comunitárias específicas, através da adaptação de algumas ferramentas e métodos específicos utilizados; outro fator a ser considerado neste ambiente de Codesign referenciado é a sua relevância para promoção do engajamento social nas questões urbanas, o que aproxima também seus resultados das expectativas que são buscadas ao se promover iniciativas de caráter educacional em áreas de patrimonialização e/ou centros históricos a serem preservados.

\section{Considerações Finais}

A realização desse trabalho mostra que os dispositivos de diálogo propostos principalmente por Manzini (2017) e Halse (2013) são utilizados para facilitar a comunicação e relacionamento entre os pares de co-pesquisadores, a criação de ferramentas de teste são estratégias lúdicas que favorecem a comunicação e autonomia, além de estimular a proposição de novas soluções e artefatos artesanais para experimentação que podem ser criadas pelos próprios agentes comunitários, o que torna o ambiente urbano também um cenário de Design, que permite uma troca de conhecimentos, criação e intervenção social sustentável.

É possível perceber a relevância do método para o engajamento comunitário diante dos projetos que envolvem questões urbanas e sociais, dessa forma, pode-se caracterizar a presente abordagem metodológica como imprescindível para preservação das culturas e valorização da identidade e valores humanos de todos que participam deste processo.

Nota-se que o resultado foi satisfatório e positivo das iniciativas apresentadas, uma vez que os participantes demonstraram interesse e curiosidade por se manter envolvidos no ambiente colaborativo de trabalho, além de eles mesmos terem oferecido estratégias de mudança e feito a proposição de novas ferramentas de teste, o que comprova que o aprendizado se torna um processo espontâneo e dinâmico, e que a troca de conhecimentos e saberes se sobrepõe às hierarquias academicista e econômicas, uma vez que todos os envolvidos, pesquisadores de Design ou agentes comunitários buscam o mesmo benefício: desenvolvimento urbano e social associado à preservação da cultura.

Através da análise das iniciativas bem sucedidas que foram apresentadas na Dinamarca, e no Rio de Janeiro no viés urbano e ambiental, é possível prever um itinerário educativo no que tange o patrimônio que possa ser adaptado também a sítios históricos e que seja efetivamente colaborativo, ou seja, criado em concordância com as necessidades e expectativas da comunidade e ao mesmo tempo eficaz para a preservação do patrimônio, visto que, o histórico de iniciativas educativas já implementadas ao longo dos últimos 10 anos na cidade de São Luís - MA não se mostraram eficazes em sua manutenção. Desse modo, o ponto forte de incentivo à aplicação da abordagem é que os próprios colaboradores da pesquisa criam alternativas, questionamentos e novas soluções para o seu contexto social e realidade cultural a ser preservada.

\section{Referências}

IPHAN. Patrimônio Patrimônio mundial: fundamentos para seu reconhecimento A convenção sobre proteção do patrimônio mundial, cultural e natural, de 1972 : para saber o essencial. __ Brasília, DF : Iphan, 2008.

COSTA, Andrea Katiane Ferreira. Ações educativas e práticas preservacionistas no Centro Histórico de São Luís no período de 1995-2008, São Luís-MA: EDUFMA,2016. 
EHN P.; Learning in participatory Design as i found it. In: BONSIGNORE E; DISALVO B; DiSALVO C; IYP J. (Orgs.) In: Participatory Design for Learning: Perspectives from Practice and Research . New York : Taylor\&Francis, 2017.

FIGUEIREDO, Margareth ; VARUM, Humberto; COSTA, Aníbal. Caracterização das técnicas construtivas em terra edificadas no século XVIII e XIX no centro histórico de São Luís (MA, Brasil). ARQUITETURA REVISTA UNISINOS, [S. I.], 2011. Disponível em: http://revistas.unisinos.br/index.php/arquitetura/article/view/1280. Acesso em: 14 mar. 2019.

HALSE,J. Ethnographies of the Possible in: Design Anthropology Theory and Practice. GUNN, W; OTTO T; SMITH R. An imprint of Bloomsbury Publishing Plc, Bloomsbury Academic, 2013.

PELEGRINI, Sandra C. A. Cultura e natureza: os desafios das práticas preservacionistas na esfera do patrimônio cultural e ambiental. Revista Brasileira de História, [S. I.], 2006. Disponível em: http://dx.doi.org/10.1590/S0102-01882006000100007. Acesso em: 14 mar. 2019.

MANZINI, Ezio. Design: quando todos fazem design: uma introdução ao design para inovação social - tradução Luzia Araújo - São Leopoldo, RS: Editora UNISINOS, 2017.

PAPANEK, V. Design for the Real World: Human Ecology and Social Change. Gram-Bretanha, Thames \& Hudson, 1975.

SPINUZZI, Clay. The Methodology of Participatory Design. Research gate, Washington, p. 163-174, 4 maio $2005 . \quad$ Disponível em: https://www.researchgate.net/publication/233564945_The_Methodology_of_Participatory_Desig n. Acesso em: 10 abr. 2019.

VENTURA, Liana; SZANIECKI, Barbara; TIBOLA, Talita. Co-design no Rio de Janeiro: experimentando o espaço público como espaço comum. XVII ENANPUR, São Paulo, 2017. Disponível em: http://anais.anpur.org.br/index.php/anaisenanpur/article/view/2041/2020. Acesso em: 17 abr. 2019. 